\title{
STEM EDUCATION AND MINI WATER HEATER ON \\ PROJECT BASED LEARNING FOR RENEWABLE \\ ENERGY, SDGS TO IMPROVE \\ AWARNESSPLASTIC WASTE
}

NUR FITRIANA

\author{
SD NEGERI DERESAN SLEMAN - YOGYAKARTA INDONESIA \\ (Primary School Teacher)
}

fia.c3thi7@gmail.com

\begin{abstract}
The learning activities using STEM studies and simple media of mini water wheel were make students enthusiastic to learn about mathematics and science related to the Volume also renewable and non-renewable natural resource. Activities and learning processes were very pleasant and always motivate students to learn and think independently. Mini water wheels is media learning with STEM Education to solve the problems in electricity energy. Students learn independently to solve the problem related to the energy efficiency, energy resiliency, and energy safety. Each student is able to interpret that natural resources are renewable energy can be utilized to generate electricity, while in reality today, especially in Indonesia greatest source of electrical energy is still using coal. With this lesson students understand that nonrenewable energy could deplete, energy-saving behavior as early as possible means helping the resilience of the availability of energy and able to exploit the natural resources that exist in the school or in the home environment.

Water resource for alternative energy could prevent air pollution from coal burn and also prevent global warming. Learning process from early aware about sustainable development goals is very important to increasing knowledge and life skills about SDGs and connection in education to primary school students. Not only to make joyful and meaningful learning but students can aware about environment and aware about energy resiliency especially electricity energy the biggest need energy in the daily lives. STEM education can improve the critical thinking of students to make solution in resiliency of electricity energy.
\end{abstract}

Keyword :

STEM education, SDGs, Mini WaterHeater, PBL, Electricity Energy. 


\section{INTRODUCTION}

Energy efficiency is crucial for sustainable development for productivity of future environment which will be carried out by their well educated people regarding this issue. In school education, there are limited programs for energy efficiency. In the traditional science education, energy used to be limited to the topic of Physics subject. On the other hand, on the current context of economic science and social engineering, energy efficiency is calculated by the economic and environmental cost for designing future welfare. There is necessity to develop the textbook at school level to treat energy efficiency relevantly to the current global demand.

Students now will be leaders in the next future. In line with that, therefore Ki Hadjar Dewantara (Majelis Luhur Persatuan Taman Siswa, 1977), the first Minister of Education of the Republic of Indonesia, who has been known widely in Indonesia as a national education father, stated that: 'Knowledge and cleverness are not the aims and goals of education; but there are only the tools. The flowers that will become fruits should be prioritized. The fruits of education are the mature in the mind of our children that will help them in their daily life and that will be useful for other people. It is clear that the maturity in deciding and ready to work cooperatively with other people will become the first importance.

In line with that, in Japan (Isoda \& Katagiri, 2012:31) stated that the aim of education as follows:

"... To develop qualifications and competencies in each individual school child, including the ability to find issues by oneself, to learn by oneself, to think by oneself, to make decisions independently and to act. So that each child or student can solve problems more skillfully, regardless of how society might change in the future."

Imagine the future of the Indonesian next generation. To anticipate the next generation's need, Minister of Education and Culture of the Republic of Indonesia (Kemdikbud, 2014) has stated that graduate students in Indonesia should be new generation which are independent and should have good character. In order to achieve those aims, it is important that every students in Indonesia should be given opportunity to learn to solve problem and to learn to invent, discover, explore, experiment and investigate. In the next future, it cannot be denied that the ability to think and to reason is very important to everyone.

However, many mathematics educators focus on skills and offer mostly procedural practice. This form of instruction focuses on a lot of memorization and skill-and-drill practice. Teachers offer lecture type instruction and then students complete the pages in the texts during class time. The conclusions of the research conducted by Shadiq (2010:56-57) stated that most teachers of mathematics in their schools use or implement the traditional ways during the learning and teaching process of mathematics. They still use the paradigm of transferring knowledge from teachers' brain to students' brain.

Another type of mathematics program leans more toward exploration of mathematical concepts through conceptual investigation. Students use concrete 
materials, such as manipulative, and participate in experiments and kinesthetic demonstrations that exhibit mathematical concepts. This type of mathematics program matches to constructivism, the current issue in mathematics education. According to the Minister of Education and Culture of the Republic of Indonesia (Kemdikbud, 2014), the ultimate goal of schooling is to help and facilitate children to be independent in their real life situation. It means that in order to achieve those goal, it is important that every students in Indonesia and SEAMEO member countries should be given opportunity to learn to solve problem and to learn to invent, discover, explore, experiment and investigate during the teaching and learning of mathematics in the real class. In line with that issue, Haylock and Thangata (2007:35), stated that constructivism focuses attention on the pupil's learning rather than on the teacher's teaching. In Japan (Isoda \& Katagiri, 2012:1) stated that Problem Solving Approach (PSA) can be implemented to help learner to develop mathematical thinking.

In Indonesia, the objective of compulsory mathematics program are to help and facilitate learners to have a positive attitude and personal qualities needed to succeed in life, and has the knowledge and basic mathematics skills in communicating, arguing, and problem solving by using mathematics needed in their daily life and further education. However the results of TIMSS 2007 (Kemdikbud: 2012b: 14) shows that only $5 \%$ of Indonesian students who can work on the problems in the high category and advance level [requires reasoning], while $71 \%$ of Korean students could. In addition to Indonesia, only $78 \%$ of students can work on the problems in the lower categories that require only rote learning, so it is necessary to develop a curriculum that requires the effort to strengthen the reasoning ability. Kemdikbud: (2012A: 11) also stated the need of change in the process of learning from teacher-centered to process-centered to learner. The change of the textbook which contains only the subject matter to the textbook that includes the learning materials, assessment systems and competencies expected. In elementary level, Government also ask teachers to implement integrative thematic approach to all subjects in Grade 1 to Grade 6 in 30\% of chosen elementary school in Indonesia.

However, to change and to improve the quality of teaching and learning process from a "typical" mathematics classroom to the new one and more innovative is not easy. The factor that should be taken into account is teachers' view and beliefs. In other words, the process of teaching and learning of mathematics in the classroom will be largely determined by teachers' view and beliefs about mathematics and mathematics education. Frei (2008:8), for example, stated that often teachers feel comfortable teaching the way they were taught. It is what they remember and what they know, so it becomes the way they teach, regardless of whether they believe it is the correct way to teach.

To change and improve the quality of teaching and learning process from a "typical" or "traditional" mathematics classroom to the new one and more innovative is not easy. Teachers need to experience mathematics in ways that they will be expected to teach it. Mathematics teachers need concrete examples that can be 
used and implemented in mathematics classes. Teachers are more likely to implement the new approaches in their own classes if they have experienced it in their own learning experiences.

Anthony Murphy (2011), Executive Director of the National Center for STEM Elementary Education, notes that

We need to begin STEM education early with our children, certainly in elementary school and possibly even younger. Children ... are natural scientists, engineers, and problem- solvers. They consider the world around them and try to make sense of it the best way they know how by touching, tasting, building, dismantling, creating, discovering, and exploring. For kids, this isn't education. It's fun! Yet, research documents that by the time students reach fourth grade, a third of boys and girls have lost an interest in science. By eighth grade, almost 50 percent have lost interest or deemed it irrelevant to their education or future plans ... . That means that millions of students have tuned out or lack the con dence to believe they can do science [or pursue a future in STEM]. (Murphy, 2011, para. 5)

After examining a variety of elementary STEM programs across the nation, DeJarnette (2012) suggested that elementary STEM education be greatly expanded to help foster an interest in STEM subject areas for continued interest among students. She further noted that students who complete STEM programs in high school have a greater likelihood of continuing in STEM elds for college and careers, and the same likelihood would occur between the elementary school and the middle school if STEM programs were expanded during the early grades. The goal of educators now should be to look at increasing the number of students interested in STEM programs in middle school and high school; therefore these concepts should be presented at the elementary grade level (DeJarnette, 2012). Effective teachers with content knowledge in STEM play a key role in student achievement. Almost all of these secondary STEM teachers have a degree or minor in one of the STEM disciplines, but elementary teachers are generalists and typically major in education. (Murphy, 2011, para. 7) So, it should not be a surprise to anyone that teachers at the elementary level are somewhat apprehensive about teaching STEM-in large part, they were not prepared to teach STEM effectively (Murphy, 2011).

Based on the explanation above, concerning the energy efficiency, security and resiliency, the questions can be aroused were: How to increase the awareness of Indonesian students on the danger of disasters in their daily lives? How to help and facilitate Indonesian students with the scientific and practical knowledge about disaster risks (before, during, and after the disasters) and related skills to reduce or minimize it? How to increase Indonesian students' beliefs on the importance of mathematics, science, and technology that will motivate them having good attitudes toward mathematics, science, and technology in their daily lives? Finally, how to increase the awareness of Indonesian students on energy efficiency, security, and resiliency. The purpose are increase the awareness of Indonesian students on the issue of energy efficiency in real live, help and facilitate Indonesian students with the 
scientific and practical knowledge regarding energy efficiency and related skills to reduce or minimize the use of energy, increase Indonesian students' beliefs on the importance of mathematics, science, and technology that will motivate them having good attitudes toward mathematics, science, and technology, increase the awareness of Indonesian students to predict and anticipate the energy efficiency issue.

\section{METHODOLOGY}

Focus on problem-solving. In Indonesia, MoNE (2006) states that problem-solving approach should be a focus during the teaching and learning of mathematics which includes how to help children to learn, to solve a close problem with a single solution or an open problem with various solutions. In line to that statement, Isoda \& Nakamura (2011) stated that the PSA (Problem-Solving Approach) includes: (1) enabling students to apply and extend the learned ideas to new problem situation by/for themselves, and (2) teacher must accept any ideas of children if it is originated from what they already learned but allows them to talk on their demand. It is clear that the Problem-Solving Approach facilitates students to learn to think and to learn meaningfully.

Based on the problem proposed by teacher can help and facilitate students to think and enabling them to apply and extend what they have learned to new problem situation by/for themselves. In other words, those problems will help students to learn meaningfully, to think and to be independent learner. Therefore Isoda (2010) stated that teacher must accept any ideas of children if it is originated from what they already learned but allows them to talk on their demand. It is clear that those tasks, activities, or problems become heart of the lesson. The conclusion is, those tasks, activities, or problems should be well prepared. In addition, based on the problem proposed by teacher, students can continue the next step, such as estimating the ways of solutions (planning and predicting the solution) as step 2, or independent solving as step 3, explanation and comparison as step 4, and integration and application as step 5. On the second and third step, students learn to formulate problems on their own, estimating the ways of solutions and solve it, finally check results. On the fourth and fifth step, students learn to communicate their findings with each other by reflecting their teaching STEM subjects. If they themselves lack con dence, how can they impart passion and knowledge to their elementary students?

It is one thing to understand the benefits of STEM programs and to start the process to implement programs within the elementary schools. However, we must also look at the qualifications of the teachers. Integrated STEM education content and methods are not included in most of the general teacher education courses required for elementary teacher licensure (Epstein \& Miller, 2011). In order for STEM programs to be successful, we need teachers who understand the signicance and 
importance of integrated STEM along with the content areas of science, mathematics, technology and engineering (Epstein \& Miller, 2011).

Kelley (2010) noted that "There are a number of examples in technology education history of multidisciplinary and interdisciplinary efforts linking technology education with other disciplines; however, there has never been a time in technology education where multidisciplinary and inter- disciplinary efforts are not only promising but also may be essential for the prosperity of technology education. (p. 2) “

Problem-Based Learning in the Elementary Grades, focuses on the importance of science in the elementary classroom and building a strong foundation of science understanding by integrating the STEM disciplines through a problem-based approach within the elementary curriculum. Students learn about the theoretical frameworks, research, resources, and methods related to appropriate and effective classroom practice. Students are provided with opportunities to apply science toward solving human and environmental problems and how the unique developmental needs of young children may be met through an integrated problembased methodology that uses mathematics, technology, and engineering to develop scientic solutions.

Early elementary school interest in the STEM certi cate program has expanded at a similar rate with one elementary school launching an elementary STEM laboratory and another elementary school developing a plan to enroll all teachers in the certificate program in the fall of 2013. SD Negeri Deresan (primary school) in grade 5 with 27 students and grade 2 with 26 students learn about energy efficiency using STEM education, and from result and analyzing score that found from pre test and post test are increase when they using media learning mini water heater to learn about STEM education.

\section{FINDING AND SIGNIFICANCE}

Implementation of Mathematics Teaching and Learning Integrated with Energy Efficiency, Safety, and Resiliency.The learning process in grade five of SD NegeriDeresan, Depok, Sleman used the simple MiniWaterheater to shows that solar energy can be converted into electrical energy. Environment around the home and school which is many solar sources can be used to generate electrical energy being the reasons for selecting the media. Rather than go to the real source, the teacher brought the media in the classroom to improve their understanding of costeffective energy-saving integrated into mathematics and science. It is the alternative way to minimize the risk that would be happen if students went to the real solar source.This learning activities have been carried out for 3 meetings. At the first meeting, students learnt to calculate the area and identify the volume cubeetc.ruler is used in order students have better understanding of the volume concept. They don't have to memorize the formula of the area as the basic concept. While for the science subjects they learnt to identify the sources of renewable and non -renewable energy and manner of saving energy in their daily lives both in the home and school 
environment. At the second meeting, students designed simple water heater using paper wasteand plastic waste, which previously they had design the shape, volume , and the design of container using plastic and alumunium foil..

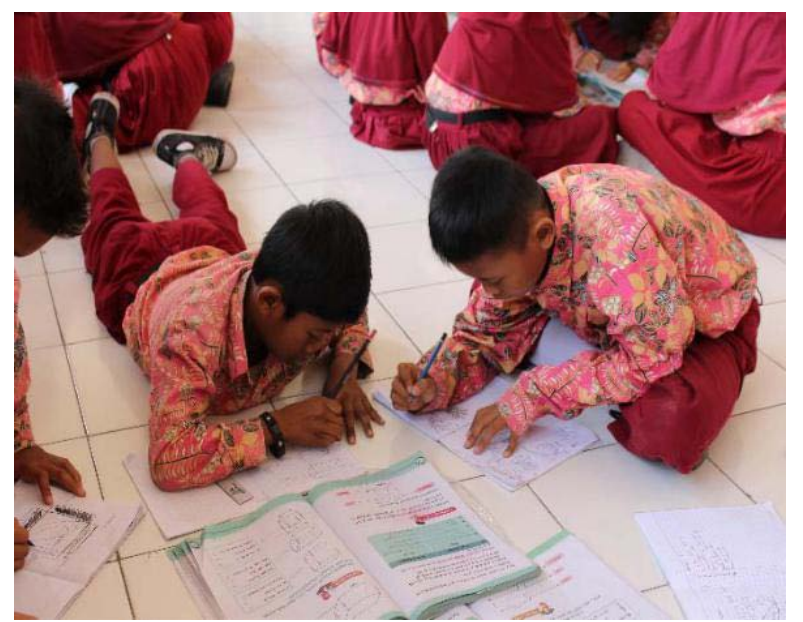

Figure 1. Students Designed Simple Waterheater

Using plastic and paper waste In this learning process all the students are very enthusiastic to arrange the water heater best design to get best result in accordance with the creation of their group with the plastic and alumunium foil to make square, rectangle or triangle, shapes, and sizes. Each group arrange the blade using the paper, pipe and plastic with water container from plastic bottle inside to change save water using solar energy into replace electrical energy by connect the water wuith thermometer. The solar energy generated can be seen from the thermometer.

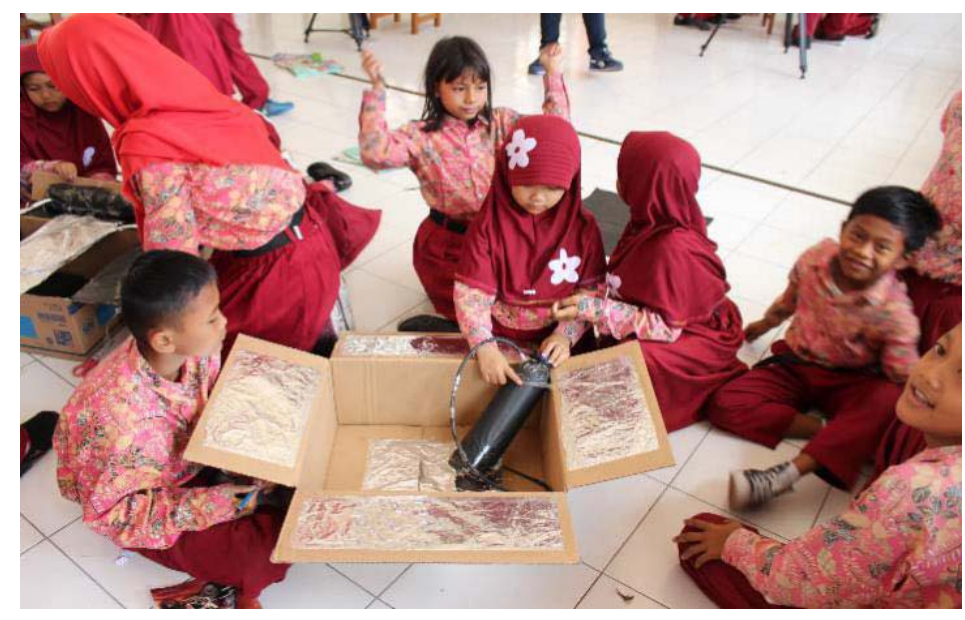

Figure 2. Students Arrange mini water heater 


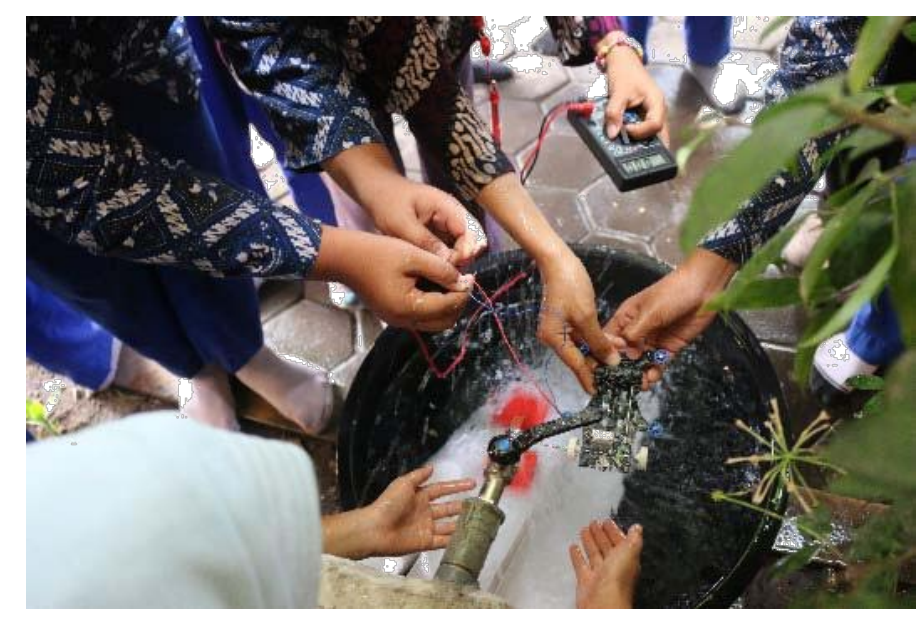

Figure 3. Students Record the temperature solar Energy Generated

Each student tried to observe the difference of design generated among the design and shape designed. How many themperature. They should record the difference of the themperature energy solar produced. They also compare with a different shape and volume of the mini waterheater to see the difference themperature. They were very enthusiastic and curious whenever conducting the experiment. They tried to do the experiment for several times to get the accurate result and also pose some question if they found difficulties during the experiment.

They also discuss what causes the difference in solar energy produced. The role of teacher is just as facilitator. Teacher pose questions that provoke their curiosity to try and find their own conclusions from the activities. Debriefing process occurs with enthusiasm and occurs not only between teachers and students but among groups with one another through a presentation made by each group.

From the experiment, there are some findings come from the students:

- The test probes of the thermometer should be best design .The plastic blackcatch the sunlight and the allumunium foil to sprout the light. They realize the thermometer doesn't work if they not touch the water .

- water heater container must be ensured that it does not leak so water does not drip.

- water heater containers that are wrapped in black plastic the water temperature is hotter than the one wrapped by aluminum foil. that's because the black plastic wrap can maintain the heat of the water inside.

- the difference in design causes the reflection of the light to be different so that the reflection of light produced by aluminum foil must be wider and focused on the mini water heater container which is a plastic bottle that has been filled with water. 
The conclusions and findings of each group to be discussed as well as an input for every group in order to improve the design of the waterwheel blades. Based on the

findings, they have to redesign the model developed to produce greater temparature energy than the previous one. They did it at the last meeting. At that time, they also did experiment to compare the temperature energy generated to the previous one. The learning process is fun for students because they are not burdened with memorizing formulas in calculating the volumeand water discharge . In addition, they are also becoming more frequent interpret that the energy they use in everyday life is still comes from non-renewable energy, namely coal, which is indirectly from the combustion of coal would also result in air pollution and availability coal over time will run out. Students also interpret that the use of alternative energy should not be costly and wait for the availability of energy runs out first, but utilizing renewable energy sources as a source of energy is one example of how we can maintain the resilience of energy supply today. Students also understand that the habits of energy-saving behavior in their daily lives indirectly could save costs. Just as in the use of electrical energy costs would also increase. Familiarize students with "Save Energy, Save Costs" early on, invites them to think critically, creatively, and cares about the environment. It is an interesting learning process for students to think to solve the existing problems in their own way, so that they will feel that what they do have an important role in the effort to save energy.

Discussion method used in this learning process is very effective to improve their skill to express and respect to the other opinions and to work together. Here, the teacher ensure that no student is dominating the learning process. All of them share and learn each other. At the time of the experiment students also encouraged to have a sense of good competition so that they worked together in order to produce or showed the best.

The presentation session also encouraged students to be more confident in presenting the findings they have discovered independently. During this session, they learnt to be a big hearted student in accepting inputs or suggestions from others. This study combines quantitative and qualitative methods. The quantitative method used to measure the level of students' understanding of the material, calculate the volume as mathematics concept and behavior of energy saving in their daily lives as well as to recognize the potential of renewable energy sources related to renewable and nonrenewable natural resources concept in science subjects through the existing value in the post-test and pre -test. The results of pre-test and post-test shows increases in value. It means that students are able to understand the material with the theme of energy that have been studied.

\section{CONCLUSION}

The learning activities using STEM studies and simple media of waterheater were make students enthusiastic to learn about mathematics and science related to 
STEM activity about Volume and debit of flow, temperature of water also renewable and non-renewable natural resources. In addition to learn the two subjects that exist in the curriculum, the students also indirectly can learn about the technology namely simple waterwheel media that can be used to charge mobile phones and also on engineering where students learn how solar energy turned into electrical energy using sunlight/ solar panel, with indicator electrical energy using thermometer.

Activities and learning processes were very pleasant and always motivate students to learn and think independently. The materials used to arrange the media is a familiar materials for students. They can find them in their daily lives and take advantage of second-hand goods.

The discussion session build up students' confidence to analyze and arrange the waterwheel blade. Students learn independently to solve the problem related to the energy efficiency, energy resiliency, and energy safety. Each student is able to interpret that natural resources are renewable energy can be utilized to generate electricity, while in reality today, especially in Indonesia greatest source of electrical energy is still using coal. With this lesson students understand that nonrenewable energy could deplete, energy-saving behavior as early as possible means helping the resilience of the availability of energy and able to exploit the natural resources that exist in the school or in the home environment.

\section{RECOMMENDATION}

For further research, waterheater media can be developed to modify the current source of Solar Energy that may not only use plastic black to catch the sunlight but can also use paper black. To make pipeor water container, researcher can use bigger and stronger material so that the blade can't be separated if exposed to strong current flow of water. Similarly, allumunium foil that is used can be replaced using a white paper or glass/mirror to be able to produce hot water. So that could be or capable of being used to digital thermometer as a measure that the temperature is converted into solar energy capable and able to generate electric energy.

The theme of energy is very attractive for students because in their daily lives and they are often the most widely used electrical energy, energy saving behavior indirectly also make students behave in a cost-effective, because it is closely related to the payment of electricity bill. One way of saving energy in addition to energysaving behavior in their daily lives can also use a simple alternative energy corresponding potential that exists in the environment, can be derived from wind, water and solar energy. 


\section{REFERENCES}

DeJarnette, N. K. (2012). America's children: Providing early exposure to STEM (science, technology, engineering and math) initiatives. Education, 133(1), 77-84.

Epstein, D., \& Miller, R. T. (2011). Slow off the mark: Elementary school teachers and the crisis in STEM education. Education Digest, 77(1), 410.

Epstein, D., \& Miller, R. T. (2011). Slow off the mark: Elementary school teachers and the crisis in STEM education. Education Digest, 77(1), 410.

Haylock, D. \& Thangata, F. (2007). Key Concepts in Teaching Primary Mathematics. London: SAGE Publications Ltd.

Isoda, M. (2010). Lesson Study. What Is It and How Can We Develop? From Japanese and APEC Experience. Power Point, presented at QITEP in Mathematics.

Tsukuba: University of Tsukuba, Center for Research in Educational Development.

Isoda, M. \&Katagiri, S. (2012). Mathematical Thinking. Singapura: World Scientific.

Isoda, M. \& Nakamura, T. (2011). The theory of Problem Solving Approach on Lesson Study for All APEC Economies on Isoda, M. \& Nakamura, T. (Chief editors): Mathematics Education Theories for Lesson Study: Problem Solving Approach through Extension and Integration (Special Issue of EARCOME 5). Tokyo: Journal of Japan Society of Mathematical Education.

Kemdikbud - MoEC (2014). GawatDaruratPendidikan di Indonesia. Power Point presented by the Minister of Education and Culture of the Republic of Indonesia in front of all the Head of Education and Culture Districts Offices. Jakarta: Kemdikbud.

Kemdikbud (2012A). Public Testing Materials of Curriculum 2013. Jakarta:

Kemdikbud.

Kemdikbud (2012B). Curriculum 2013 Development. Jakarta: Kemdikbud. 
Majelis Luhur Persatuan Taman Siswa (1977). Karya Ki Hadjar Dewantara Bagian Pertama: Pendidikan. Yogyakarta: MajelisLuhurPersatuan Taman Siswa.

MONE (2006). Permendiknas Nomor 22 Tahun 2006 TentangStandar Isi Sekolah Menengah Atas. Jakarta: Depdiknas

Murphy, Tony. (2011, August 29). STEM education—It's elementary. US

News and World Report. Retrieved from

http://www.usnews.com/news/articles/2011/08/29/stem-education--itselementary

Shadiq, F. (2010). Identifikasi Kesulitan Guru Matematika SMK pada Pembelajaran Matematika yang Mengacu pada Permendiknas No. 22 Tahun 2006. Edumat: Jurnal Edukasi Matematika, Nomor 1, Volum 1, $49-60$.

the Study of Technology. Reston, VA: Author. Kelley, T. (2010). Staking the claim for the "T" in STEM. Journal of Technology Studies, 36(1), 2-11.

\section{Appendix}

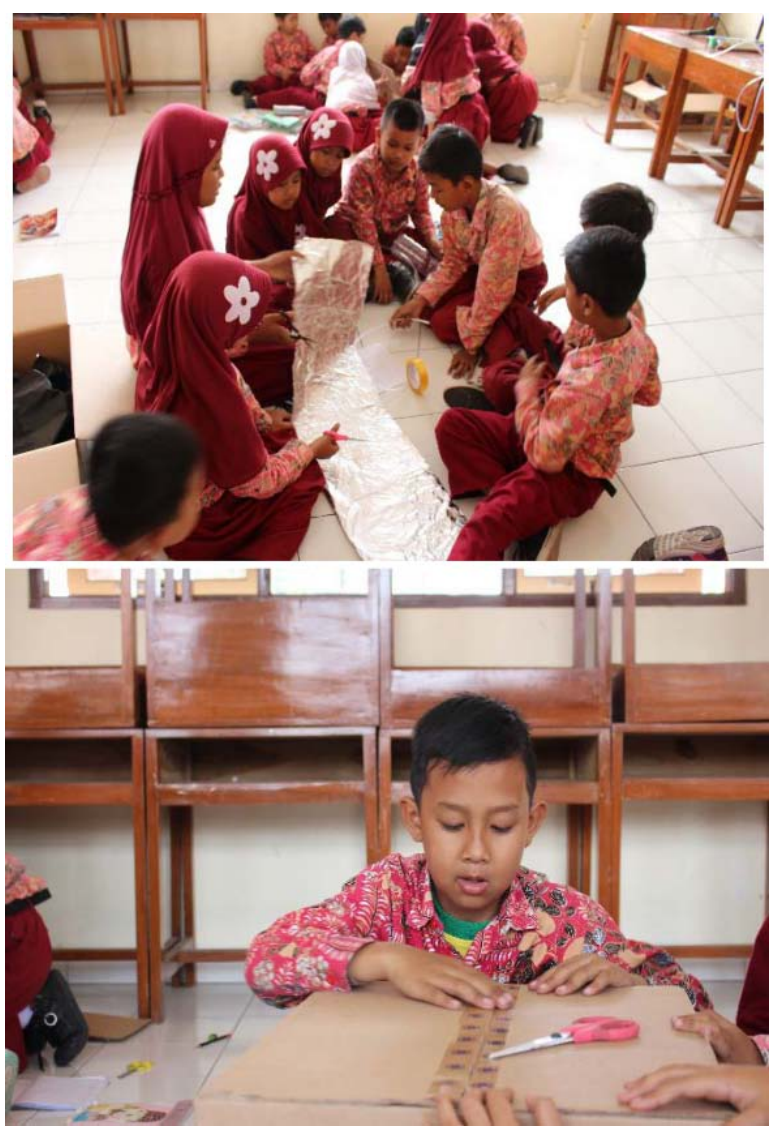



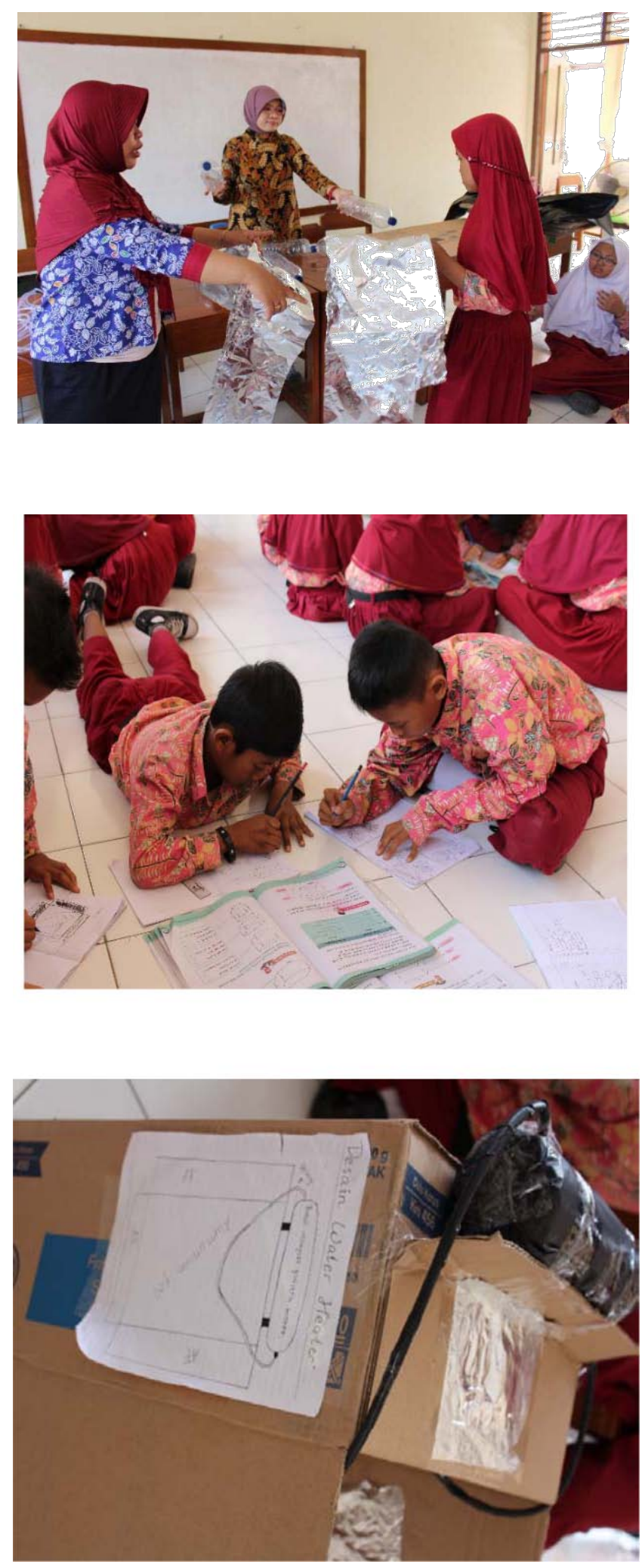

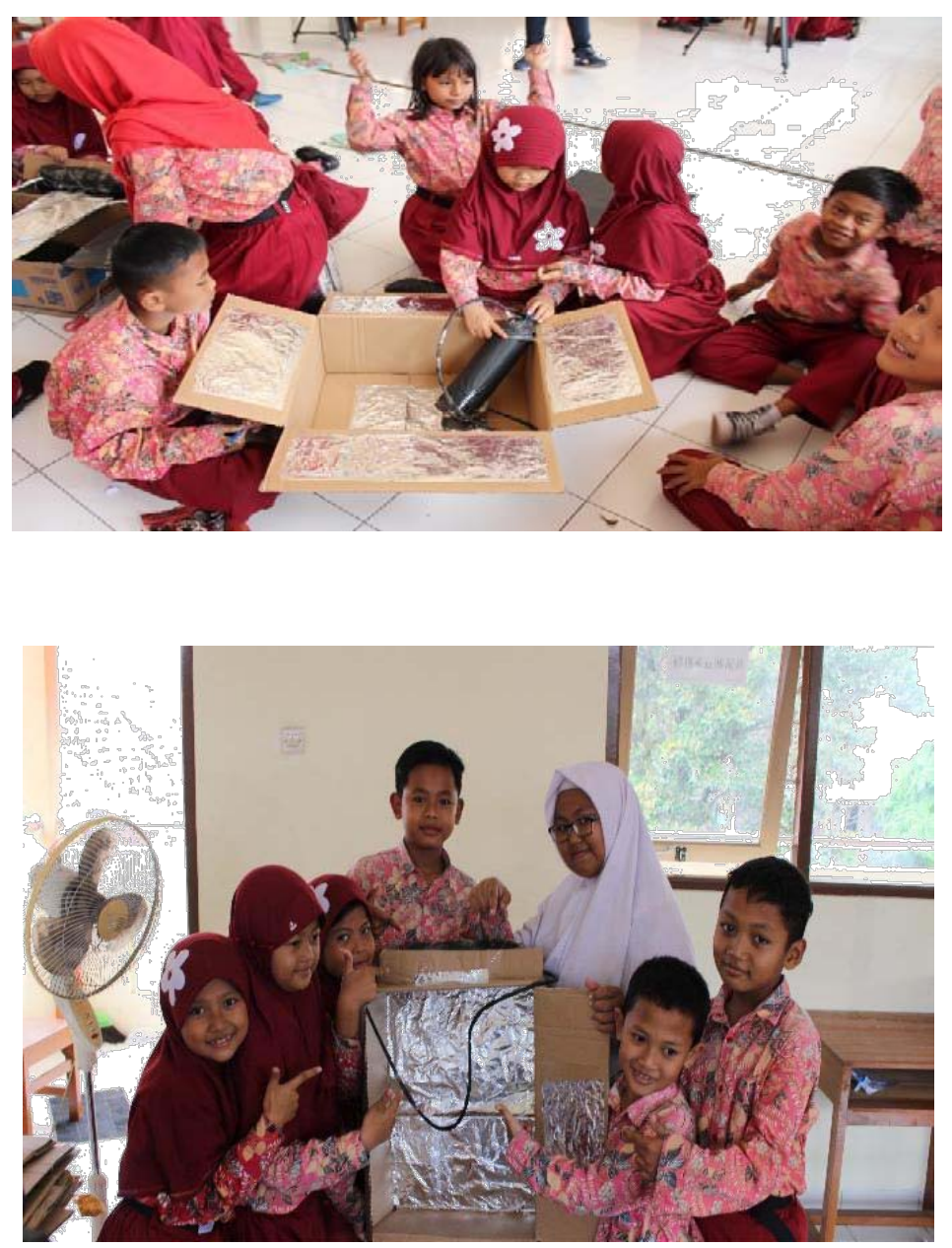